\title{
Spectral domain OCT versus time domain OCT in the evaluation of macular features related to wet age-related macular degeneration
}

This article was published in the following Dove Press journal:

Clinical Ophthalmology

8 February 2012

Number of times this article has been viewed

\author{
Luisa Pierro' \\ Elena Zampedri' \\ Paolo Milani ${ }^{2}$ \\ Marco Gagliardi' \\ Vincenzo Isola ${ }^{2}$ \\ Alfredo Pece ${ }^{2}$ \\ 'Department of Ophthalmology, \\ University Vita-Salute, Scientific \\ Institute San Raffaele, Milano, Italy, \\ ${ }^{2}$ Fondazione Retina 3000, Milano, Italy
}

Correspondence: Paolo Milani

Fondazione Retina 3000,Via Bixio 3.

20100 Milan, Italy

Tel +392 295II 378

Email dottpaolomilani@hotmail.com
Background: The aim of this study was to compare the agreement between spectral domain optical coherence tomography (SD OCT) and time domain stratus OCT (TD OCT) in evaluating macular morphology alterations in wet age-related macular degeneration (AMD).

Methods: This retrospective study was performed on 77 eyes of 77 patients with primary or recurring subfoveal choroidal neovascularization secondary to AMD. All patients underwent OCT examination using Zeiss Stratus OCT 3 (Carl Zeiss Meditec Inc, Dublin, CA) and Opko OTI Spectral SLO/OCT (Ophthalmic Technologies Inc, Toronto, Canada). In all radial line scans, the presence of intraretinal edema (IRE), serous pigment epithelium detachment (sPED), neurosensory serous retinal detachment (NSRD), epiretinal membrane (EM), inner limiting membrane thickening (ILMT), and hard exudates (HE) were evaluated. The degree of matching was quantified by Kappa measure of agreement.

Results: The percentage distribution of TD OCT findings versus SD OCT findings was: IRE $36.3 \%$ versus $77.9 \%$, sPED $57.1 \%$ versus $85.7 \%$, NSRD $38.9 \%$ versus $53.2 \%$, EM $10.5 \%$ versus $26.3 \%$, ILMT $3.8 \%$ versus $32.4 \%$, and HE $6.4 \%$ versus $54.5 \%$. The agreement was as follows: sPED: kappa value 0.15; NSRD: kappa value 0.61; IRE: kappa value 0.18; EM: kappa value 0.41 ; ILMT: kappa value 0.02 ; HE: kappa value 0.06 .

Conclusion: The agreement in the evaluation of macular lesions between the two techniques is poor and depends on the lesion considered. SD OCT allows better detection of the alterations typically related to choroidal neovascularization such as IRE, PED, ILM thickening, and HE. Consequently its use should be strongly considered in patients with wet AMD.

Keywords: spectral domain, OCT, time domain, macular degeneration, AMD

\section{Introduction}

Although fluorescein angiography remains fundamental in determining the presence of choroidal neovascularization $(\mathrm{CNV})$, many recent studies include optical coherence tomography (OCT) to investigate the severity of exudative macular pathologies, to evaluate the possibility of retreatment, and to monitor the response to anti VEGF therapy during follow up..$^{1-3}$

In recent years the development of high-speed detection techniques (such as spectral domain [SD] OCT) has led to a significant improvement in OCT imaging performance, providing more detailed information on intraretinal morphology with respect to the first generation time domain (TD) OCT. ${ }^{4-9}$

The aim of this study was to assess the agreement between SD OCT and TD OCT in evaluating the CNV-related alterations in wet age-related macular degeneration (AMD). 


\section{Materials and methods}

This retrospective observational study was performed on 77 eyes of 77 patients ( 34 men, 43 women, mean age $74.3 \pm 9.7$ years) affected by wet AMD attending our department between June and December 2009. The research adhered to the tenets of the declaration of Helsinki. All patients signed a written consent to permit the use of the images for this study. In order to qualify for the study, the patients were required to have primary or recurring subfoveal CNV secondary to AMD. Exclusion criteria were other types of $\mathrm{CNV}$ and the coexistence of any other macular diseases.

All patients underwent OCT examination using two OCT devices: TD OCT (Stratus OCT 4.0.1, Carl Zeiss Meditec Inc, Dublin, CA) and SD OCT (OCT/SLO Opko/ OTI, Ophthalmic Technologies Inc, Toronto, Canada). TD OCT uses a near-infrared frequency light of $820 \mathrm{~nm}$, with an axial resolution of $10 \mu \mathrm{m}$ and speed of $400 \mathrm{~A}$-scans/sec. The light source of the SD OCT/SLO OTI is a modified super luminescent diode at a wavelength of $840 \mathrm{~nm}$. The axial resolution is $5 \mu \mathrm{m}$ and the transverse is $16 \mu \mathrm{m}$. The speed is set at $28000 \mathrm{~A}-\mathrm{scan} / \mathrm{sec}$; every B-scan is composed of 512 A-scans. The OCT is coupled to a scanning laser ophthalmoscope (SLO). A single experienced examiner performed the OCT examinations with a standard protocol for the two tools on the same day. Using the TD OCT and the SD OCT every eye in this study underwent the radial lines acquisition protocol after centering the scans on the fovea. If doubt about the presence or the nature of a lesion aroused, a single radial scan was used by the examiner to move the scan and investigate the lesion itself. The images were then recorded on the OCT computer and subsequently observed and analyzed using display intrinsic to TD OCT and SD OCT by two independent experienced examiners unaware of the purpose of the research who evaluated the presence of intraretinal edema (IRE), serous pigment epithelium detachment (PED), neurosensory serous retinal detachment (NSRD), epiretinal membrane (EM), inner limiting membrane thickening (ILMT), and hard exudate deposition (HE). Possible disagreement was resolved after discussion, so that investigators agreed on all the images.

IRE was defined as a diffuse or localized hyporeflective area inside the neuroretina. PED was characterized as a dome-shaped lesion of the retinal pigment epithelium layer. NSRD showed up as a hyporeflective area between the retinal pigment epithelium and all the superior retina layers, and EM was consistent with a high reflective line on the inner layer of the retina. ILMT was viewed as a high reflective band between the vitreous and the retinal layers. HE was revealed as high reflective round or oval intraretinal lesions.

The extent of the match between the two evaluations was quantified by the Kappa measure of agreement. The Chi-square was used to evaluate links between the parameters.

\section{Results}

The percentage of distribution is listed in Table 1. In particular, IRE was detected by TD OCT in 28 eyes $(36.3 \%)$ and by SD OCT in 60 eyes $(77.9 \%)$. PED was discovered by TD OCT in 44 eyes $(57.1 \%)$ and by SD OCT in 66 eyes $(85.7 \%)$. NSRD was shown by TD OCT in 30 eyes (38.9\%) and by SD OCT in 41 eyes (53.2\%). EM was evidenced by TD OCT in 8 eyes $(10.5 \%)$ and by SD OCT in 20 eyes $(26.3 \%)$. ILMT was visualized by TD OCT in 3 eyes (3.8\%) and by SD OCT in 25 eyes (32.4\%). HE was identified by TD OCT in 5 eyes $(6.4 \%)$ and by SD OCT in 42 eyes (54.5\%).

The agreement rate for each OCT feature is reported in Table 2. More specifically, the presence of PED: kappa value 0.15 ; presence of NSRD: kappa value 0.61 ; presence of IRE: kappa value 0.18; presence of EM: kappa value 0.41; presence of ILMT: kappa value 0.02; presence of HE: kappa value 0.06 .

\section{Discussion}

OCT has become increasingly useful in the diagnosis and the treatment of AMD. The recent advent of SD OCT has increased the hope to obtain a more reliable tool in an attempt to define the changes in $\mathrm{CNV}$ activity ${ }^{5,10-14}$ and, consequently, the possible retreatment. ${ }^{3} \mathrm{Also}$, OCT can provide quantitative and qualitative information regarding CNV-related features, and the introduction of SD technology has led to a remarkable improvement in lesion imaging due to improved definition of the scanned images. ${ }^{5,10-14}$

Table I Percentage distribution of the lesions

\begin{tabular}{lll}
\hline & TD OCT & SD OCT \\
\hline IRE & $36.3 \%$ & $77.9 \%$ \\
SPED & $57.1 \%$ & $85.7 \%$ \\
NSRD & $38.9 \%$ & $53.2 \%$ \\
EM & $10.5 \%$ & $26.3 \%$ \\
ILMT & $3.8 \%$ & $32.4 \%$ \\
HE & $6.4 \%$ & $54.5 \%$ \\
\hline
\end{tabular}

Abbreviations: TD OCT, time domain optical coherence tomography; SD OCT, spectral domain optical coherence tomography; IRE, intraretinal edema; sPED, serous pigment epithelium detachment; NSRD, neurosensory serous retinal detachment; EM, epiretinal membrane; ILMT, inner limiting membrane thickening; $\mathrm{HE}$, hard exudates. 
Table 2 Kappa measure of agreement between TD OCT and SD OCT

\begin{tabular}{ll}
\hline & Kappa value \\
\hline IRE & 0.18 \\
SPED & 0.15 \\
NSRD & 0.61 \\
EM & 0.41 \\
ILMT & 0.02 \\
HE & 0.06 \\
\hline
\end{tabular}

Abbreviations: TD OCT, time domain optical coherence tomography; SD OCT, spectral domain optical coherence tomography; IRE, intraretinal edema; sPED, serous pigment epithelium detachment; NSRD, neurosensory serous retinal detachment; $E M$, epiretinal membrane; ILMT, inner limiting membrane thickening; $H E$, hard exudates.

The two generations of OCT, TD and SD, have been largely investigated in order to evaluate repeatability and reproducibility of the examinations in many macular diseases, but the varying patterns of exudation secondary to AMD make OCT examination difficult to compare when performed with the same or more instruments. In fact some authors compared TD and SD macular thickness measurements findings obtained in different sessions and questioned the repeatability of the results. ${ }^{15-18}$ It has also been demonstrated by Giani et al that retinal thickness measurements obtained by various OCT devices such as Stratus and Cirrus (Carl Zeiss Meditech Inc), Spectralis (Heidelberg Engineering Inc, Heidelberg, Germany) and 3D-OCT-1000 (Topcon Corporation, Tokyo, Japan) are different due to the analysis algorithms used to set retinal inner and outer boundaries. ${ }^{18}$ Nevertheless, Eriksson et al recently suggested the use of software for manual correction of foveal position when using Cirrus SD OCT (Carl Zeiss Meditech Inc) to reduce the variability of the measurements. ${ }^{19}$

As a consequence, we decided not to compare the macular thickness findings but to evaluate the presence/ absence of AMD-related typical lesions when investigated by different generations of OCT. So far, to our knowledge, only Sayanagi et al compared the ability to delineate patterns of CNV activity using Stratus OCT and four different SD OCT devices, concluding that all SD OCT were statistically superior to delineate IRE presence. ${ }^{20}$ Therefore, it is not surprising that our study found that IRE was undetected by TD OCT in 32 patients (41\%). This is of great relevance as IRE is considered the key factor in treatment and retreatment decisions, ${ }^{3}$ and most of the authors assess the lesions persistent activity if intraretinal fluid is present.

No other studies investigated the relative sensitivity of TD and SD OCT in identifying the single lesions typically related to $\mathrm{CNV}$ presence, and overall our results reveal a poor agreement. Indeed, some concordance between the

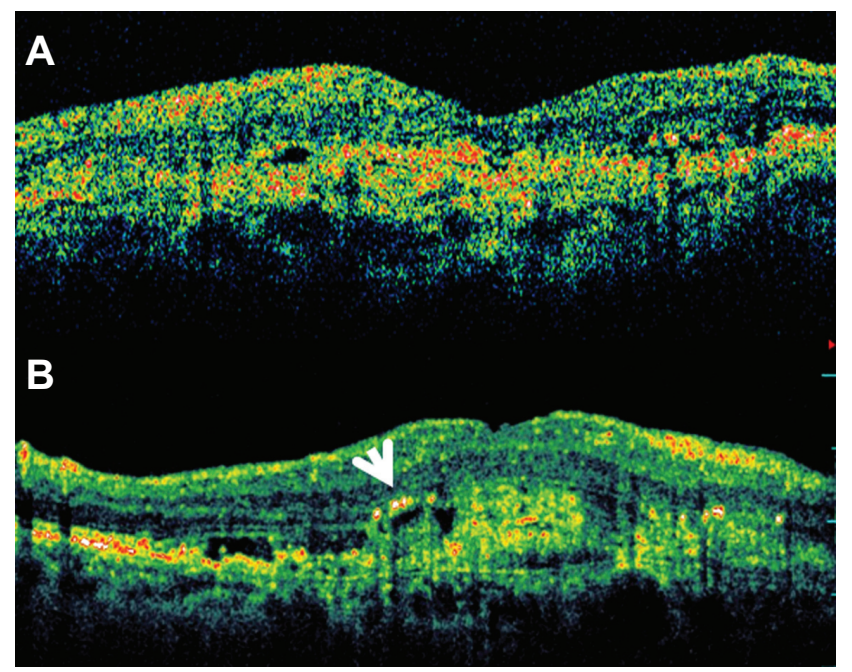

Figure I (A) Macular horizontal line scan by time domain (TD) OCT. (B) Macular horizontal line scan by spectral domain (SD) OCT. The comparison between the two OCT tools points out that hard exudates (white arrow) are visualized only by the SD device, where also intraretinal fluid cysts appear more evident and numerous. Abbreviation: OCT, optical coherence tomography.

two instruments can be found only in the identification of NSRD (kappa value 0.61) and EM (kappa value 0.41), but concordance was poor in the evaluation of IRE, PED, ILMT, and HE, where kappa value was always less than 0.2 . These results may hint that the smaller lesions are more clearly identified by SD OCT (Figure 1). In fact SD OCT, due to its improved resolution and scan acquisition, enables the smaller structures in all the retinal layers to be visualized, in particular the internal and external limiting membrane, the inner segment/outer segment of the photoreceptors, and in some cases the Bruch's membrane. ${ }^{1-13}$

A good match between the two tools has been registered only with respect to NSRD, probably because the fluid between the retinal pigment epithelium and the neuroretina is clearly serous and hyporeflective, and consequently can be easily detectable by both techniques. The moderate and slight agreement in detecting EM and ILM thickening, respectively, suggests that SD OCT more reliably detects these alterations, because of more sensitivity in visualizing the vitreomacular interface alterations, as already highlighted by some authors. ${ }^{21-23}$

This aspect could lead to better interpret the specific role of vitreomacular adhesions in the development of $\mathrm{CNV}$, which has been postulated to have an active role by some authors ${ }^{24}$ but, more recently not by others. ${ }^{25}$ Our findings, that evidenced $26 \%$ to $32 \%$ of eyes presenting with EM or ILM, respectively, at SD OCT, overall resemble the data reported by Mojana et al that included a series of 170 eyes of which $27.8 \%$ had vitreomacular adhesion. ${ }^{26}$ In that study some patients underwent macular 
peeling and they concluded that tractional forces may antagonize the effect of anti-VEGF treatment, and cause pharmacological resistance in a subpopulation of patients. Consequently we think the possibility of detecting initial thickening of vitreoretinal interface could also have some prognostic relevance.

A surprising assumption of our study is that hard exudates were visible in $54.5 \%$ of eyes when investigated by SD OCT versus only $6.4 \%$ by TD OCT. This great difference is evidently due to the greater sensitivity of SD technology, but could also lead to misdiagnosis as hyperreflective points could correspond to retinal vessels or punctate hemorrhages not visible by TD OCT. Tomographic characteristics must assist the clinician in proper diagnosis; this could prove difficult in some circumstances such as the interpretation of small pseudocysts that can masquerade as outer retina tubulation caused by photoreceptors arrangement during late stages of exudative AMD. ${ }^{27}$ It appears evident that better diagnostic capabilities allowed by SD OCT require better operator abilities, as the detection of fine morphological aspects expand the spectrum of the corresponding retinal details identification.

\section{Conclusion}

In conclusion, our findings suggest that SD OCT can better disclose a large number of retinal lesions of various types, indicating a clear advantage in the detection of tiny abnormalities of the retinal morphology.

The agreement in the evaluation of macular lesions between the two techniques is poor and depends on the lesion considered. SD OCT allows better detection of the alterations typically related to CNV such as IRE, PED, ILM thickening, and HE. Consequently its use should be strongly considered in patients with wet AMD.

\section{Disclosure}

The authors report no conflicts of interest in this work.

\section{References}

1. Fung AE, Lalwani GA, Rosenfeld PJ, et al. An optical coherence tomography-guided, variable dosing regimen with intravitreal ranibizumab (Lucentis) for neovascular age-related macular degeneration. Am J Ophthalmol. 2007;143:566-583.

2. Gupta OP, Shienbaum G, Patel AH, Fecarotta C, Kaiser RS, Regillo CD. A treat and extend regimen using ranibizumab for neovascular age-related macular degeneration clinical and economic impact. Ophthalmology. 2010;117:2134-2140.

3. Lalwani GA, Rosenfeld PJ, Fung AE, et al. A variable-dosing regimen with intravitreal ranibizumab for neovascular age-related macular degeneration: year 2 of the PrONTO study. Am J Ophthalmol. 2009; 148:43-58.
4. Ko TH, Fujimoto JG, Schuman JS, et al. Comparison of ultrahigh- and standard-resolution optical coherence tomography for imaging macular pathology. Ophthalmology. 2005;112:1922-1915.

5. Chen Y, Vuong LN, Liu J, et al. Three-dimensional ultrahigh resolution optical coherence tomography imaging of age-related macular degeneration. Opt Express. 2009;17:4046-4060.

6. Keane PA, Bhatti RA, Brubaker JW, Liakopoulus S, Sadda SR, Walsh AC. Comparison of clinically relevant findings from high-speed Fourierdomain and conventional time-domain optical coherence tomography. Am J Ophthalmol. 2009; 148:242-248.

7. Drexler W, Fujimoto JG. State-of-the-art retinal optical coherence tomography. Prog Ret Eye Res. 2008;27:45-88.

8. Wojtkowski M, Srinivasan V, Fujimoto JG, et al. Three-dimensional retinal imaging with high-speed ultra-high resolution optical coherence tomography. Ophthalmology. 2005;112:1734-1746.

9. Drexler W. Ultrahigh-resolution optical coherence tomography. J Biomed Opt. 2004;9:47-74.

10. Coscas G, Coscas F, Vismara S, Souied E, Soubrane G. Spectral Domain OCT in age-related macular degeneration: preliminary results with Spectralis HRA-OCT. J Fr Ophthalmol. 2008;31:353-361.

11. Brennen PM, Kagemann L, Friberg TR. Comparison of stratus OCT and cirrus HD-OCT imaging in macular diseases. Ophthalmic Surg Lasers Imaging. 2009;40:25-31.

12. Menke MN, Dabov S, Sturm V. Features of age-related macular degeneration assessed with three-dimensional Fourier-domain optical coherence tomography. Br J Ophthalmol. 2008;92:1492-1497.

13. Schmidt-Erfurth U, Leitbeg RA, Michels S, et al. Three-dimensional ultra-high resolution optical coherence tomography of macular diseases. Invest Ophthalmol Vis Sci. 2005;46:3393-3402.

14. Cukras C, Wang YD, Meyerle CB, Forooghian F, Chew EY, Wong WT. Optical coherence tomography-based decision making in exudative age-related macular degeneration: comparison of time- versus spectraldomain devices. Eye. 2009;24:775-783.

15. Parravano M, Oddone F, Boccassini B, et al. Reproducibility of macular thickness measurements using Cirrus SD-OCT in neovascular age-related macular degeneration. Invest Ophthalmol Vis Sci. 2010;51:4788-4791.

16. Patel PJ, Chen FK, Ikeji F, Tufail A. Intersession repeatability of optical coherence tomography measures of retinal thickness in early age-related macular degeneration. Acta Ophthalmol. 2011;89:229-234.

17. Patel PJ, Chen FK, Ikeji F, Richardson M, Cruz LD, Tufail A. Intrasession repeatability of optical coherence tomography measures in active neovascular age-related macular degeneration. Acta Ophthalmol. 2009;89:526-532.

18. Giani A, Cigada M, Choudhry N, et al. Reproducibility of retinal thickness measurements on normal and pathologic eyes by different optical coherence tomography instruments. Am J Ophthalmol. 2010;150:815-824.

19. Eriksson U, Alm A, Larsson E. Is quantitative spectral-domain superior to time-domain optical coherence tomography (OCT) in eyes with agerelated macular degeneration? Acta Ophthalmol. 2011; doi:10.1111/j. 1755-3768.2011.02112.x.

20. Sayanagi K, Sharma S, Yamamoto T, Kaiser PK. Comparison of spectral-domain versus time-domain optical coherence tomography in management of age-related macular degeneration with ranibizumab. Ophthalmology. 2009;116:947-955.

21. Koizumi H, Spaide RF, Fisher YL, Freund KB, Klancnik JM Jr, Yannuzzi LA. Three-dimensional evaluation of vitreomacular traction and epiretinal membrane using spectral-domain optical coherence tomography. Am J Ophthalmol. 2008;145:509-517.

22. Legaretta JE, Gregori G, Knighton RW, Punjabi OS, Lalwani GA, Puliafito CA. Three-dimensional spectral-domain optical coherence tomography images of the retina in the presence of epiretinal membranes. Am J Ophthalmol. 2008;145:1023-1030.

23. Michalewski J, Michalewska Z, Cisiecki S, Nawrocki J. Morphologically functional correlations of macular pathology connected with epiretinal membrane formation in spectral optical coherence tomography. (SOCT). Graefes Arch Clin Exp Ophthalmol. 2007;245:1623-1631. 
24. Lee SJ, Lee CS, Koh HJ. Posterior vitreomacular adhesion and risk of exudative age-related macular degeneration: paired eye study. Am J Ophthalmol. 2009;147:621.e1-626.e1.

25. Waldstein SM, Sponer U, Simader C, Sacu S, Schmidt-Erfurth U. Influence of vitreomacular adhesion on the development of exudative age-related macular degeneration 4-year results of a longitudinal study. Retina. November 16, 2011. [Epub ahead of print.]
26. Mojana F, Cheng L, Bartsch DU, et al. The role of abnormal vitreomacular adhesion in age-related macular degeneration: spectral optical coherence tomography and surgical results. Am J Ophthalmol. 2008;146:218-227.

27. Zweifel SA, Engelbert M, Laud K, Margolis R, Spaide RF, Freund KB. Outer retinal tubulation: a novel optical coherence tomography finding. Arch Ophthalmol. 2009;127:1596-1602.

\section{Publish your work in this journal}

Clinical Ophthalmology is an international, peer-reviewed journal covering all subspecialties within ophthalmology. Key topics include: Optometry; Visual science; Pharmacology and drug therapy in eye diseases; Basic Sciences; Primary and Secondary eye care; Patien Safety and Quality of Care Improvements. This journal is indexed on

Submit your manuscript here: http://www.dovepress.com/clinical-ophthalmology-journal

\section{Dovepress}

PubMed Central and CAS, and is the official journal of The Society of Clinical Ophthalmology (SCO). The manuscript management system is completely online and includes a very quick and fair peer-review system, which is all easy to use. Visit http://www.dovepress.com/ testimonials.php to read real quotes from published authors. 